\title{
Analysis on the Training Mode of College Enterprise Cooperation Mechanism
}

\author{
Zhuojuan Yang ${ }^{1, a}$, Youquan Chen $^{2, b}$ and Lidan Fan $^{1, c^{*}}$ \\ ${ }^{1}$ College of Mechanical Engineering Jilin Teachers' Institute of Engineering \& Technology Changchun, \\ China \\ ${ }^{2}$ Department of Mechanical Engineering Changchun Institute of Engineering Technology \\ Changchun, China \\ azhuojuan@163.com, ${ }^{\mathrm{b}}$ Quan3168@sina.com, ${ }^{\mathrm{c}}$ Fanlidan111@163.com \\ *The corresponding author
}

Keywords: School enterprise cooperation; Mechanical professional talents; Training mode

\begin{abstract}
Mechanical professional personnel training objectives are often the first line of production and manufacturing, which requires the mechanical professional training of students to have a high comprehensive quality and job skills. And based on the school enterprise cooperation, mechanical professional personnel training mode, to adapt to the requirements of mechanical professional personnel training for employment, improve the level of training and the employment rate of students. This paper discusses the necessity of school enterprise cooperation and the connotation and characteristics of the school enterprise cooperation mode, analyzes the problems existing in the implementation of this model, and puts forward the corresponding countermeasures for the problems
\end{abstract}

\section{Introduction}

With the advent of the era of knowledge economy, talent has become the most important and most valuable resource, the fact that more and more people have been recognized by more and more people. For mechanical professional talent training, how to build a sufficient quantity, structure optimization, layout reasonable, not only to meet the school of talent cultivation plan and adapt to the requirements of enterprise personnel is training is the only way for the new era of high skilled talents to adapt to our educational reform and development in an important way. This article on how to implement the cooperation between school and enterprise personnel training mode, improve the level of mechanical professional personnel training to elaborate some experience.

\section{The Necessity of Training Mode of College Enterprise Cooperation Mechanism}

Conducive to the Realization of Personnel Training Objectives. At present, there exist the problems of inaccurate positioning of professional in the engineering profession in our country, specific to the mechanical engineering, the traditional teaching mode of the lack of according to the training objectives, curriculum mostly on curriculum theory, lack of combining with practice, not only the students to learn the difficult, and easy to the knowledge of the application of doubt, which makes them have learning useless thoughts.

While the goal of mechanical professional personnel training is often the first line of production and manufacturing, which requires students to have a higher professional training of comprehensive quality and job skills. Training machinery professionals must adhere to the ability to this, and in the ability of mechanical professionals to exercise, relying on the school's traditional theory of knowledge learning is difficult to achieve. Mechanical professional personnel training objectives of requirements, and adapt to the mode of education, the remarkable characteristic of this model is to make the educated must integrate theory with practice, have a clear understanding on the whole process of the manufacturing and processing. Therefore, mechanical professional talents based on school enterprise cooperation training mode arises at the historic moment. Based on school enterprise cooperation in 
personnel training mode to break the traditional teaching mode of the closed environment, makes full use of the hardware resources of school intellectual resources and manufacturing enterprises, realize the complementary advantages, to promote the employment of graduates, in order to promote the healthy development of professional machinery and has important practical significance.

To Promote the Reform and Development of Education. At present, with the arrival of the era of knowledge economy, manufacturing of high-quality skilled talents is extremely urgent demand, it can be said that the high-quality skilled personnel, especially for the production of the first line of high-quality talent shortage, has become one of the important factors that restrict our country manufacturing industry sustainable development. At the same time, the school has become increasingly serious employment situation, the employment pressure of college graduates is becoming more and more serious problem. How to cultivate talents with real demand of manufacturing enterprises, how to enhance the competitiveness of the graduates in the employment market has become an urgent problem facing the education reform of mechanical specialty. Practice has proved, based on school enterprise cooperation in personnel training model to comply with the basic laws of mechanical engineering education, it through the combination of theory and practice to enable students to truly apply it, which not only meets the demand of talent of economic development, but also for the school to win the broad education market and development space.

The Characteristics of Mechanical Specialty Determine the Necessity of Implementing School Enterprise Cooperation. Mechanical profession has distinct practicality and practicality, it is often for the first line of manufacturing and processing services, which determines the mechanical professional personnel training must take into account the requirements of manufacturing enterprises. In addition, mechanical professional compared with other majors, for teaching and training conditions of the site has a higher requirement, but the school was often because of the limited funding and site conditions and other factors, provide facilities scale can only meet the mechanical engineering students daily study and experiment. Schools, therefore, it is necessary to implement based on school enterprise cooperation in personnel training mode, by students in what to feel and experience the enterprise real job site, for students to provide a real practice environment, so that the students can grasp the demand of the reality, in the study do have a definite object in view, to seize the key to achieve true knowledge.

\section{The Connotation and Characteristics of the Training Mode of College Enterprise Cooperation Mechanism}

The Connotation of the Training Mode of College Enterprise Cooperation Mechanism. School enterprise cooperation machinery professional talent training mode is mainly refers to the training institutions and enterprises would mechanical professionals widely, a full range of cooperation, including the optimization of training conditions, mechanical professional courses teaching content and teaching methods of reform, on the Faculty of reconfiguration and its purpose is to through cooperation with enterprises, for the students who major in mechanical engineering provide a real practice environment, so that students can link theory with practice, combine the work of learning in school and what to do in the future. This training mode not only can promote students' vocational skills training, but also help students to grasp the focus of study, and then be able to consciously create a good professional quality, and ultimately lay a solid foundation for their employment.

Problems in School Itself. The understanding of school enterprise cooperation through many schools based on the connotation of school enterprise cooperation model of talents is not enough to understand, resulting in these schools in the implementation process is often a mere formality, no machinery to the specialized teaching method and teaching mode do nature of change, of course, is also very difficult to obtain good teaching effect.

School enterprise cooperation mechanisms are not sound enough to carry out the real significance of school enterprise cooperation, the key lies in establishing a around education training target, talent standard, knowledge and ability structure, professional setting, curriculum design and teaching content and cooperative evaluation of the results of school enterprise cooperation education mechanism, and to 
ensure that this system truly carry out. These systems in the concrete teaching link is often a mere formality, substance and no real change, and some of the teaching system although established, but not easy to operation or cannot operate, there is no guarantee that are completed in a timely manner, thus losing the meaning.

Depth cooperation enough for mechanical engineering, organic combination of theory teaching and engineering practice, in imparting knowledge and cultivate students' practical ability, thus greatly reducing students graduated from the induction time. The teaching and learning process are due to enterprise participation, training to company guidance, and according to the technical requirements of post manufacturing enterprises, and enterprises to jointly study and formulate the personnel training plan, to form the enterprise jointly participate in talent training of cooperative teaching mode. In reality, some enterprise cooperation is only in the surface, the depth of cooperation needs to be improved.

Quality of teachers needs to be improved mechanical professional is a combination of theory and practice strong discipline, which requires mechanical professional teachers in has rich theoretical knowledge and rich practical experience, for a long time, school teachers mostly from a gate into another school. They are very difficult to give the students to practice guidance. Some schools through the technical backbone to recruit from the enterprise to change the situation, but the enterprise staff tend to lack a good quality of teachers, the teaching process of responsibility to be improved.

Based on the school enterprise cooperation model of teaching requirements of college teachers determine talent training scheme, the to teacher's comprehensive ability and quality put forward higher requirements, and our school machinery professional quality of teachers is still inadequate, become the important factors to restrict the improvement of teaching quality.

In recent years, our school has increased the construction of practice training base on campus, but also achieved some results, but in general, both the scale and quality, but also far from meeting the needs of mechanical professional teaching. Many of the school's internship training only superficially, far below the level of proficiency, which has become bottleneck control mechanical professional talent training quality. In addition, some colleges and universities lack of R \&amp; D capabilities, cannot really attract enterprises to carry out cooperation in training places.

Enterprises as the main micro economic, the purpose is to make profit, they are more concerned about the recent economic benefits, and rarely consider the long-term economic interests and the need for long-term business development. And considering China's current laws and regulations of school and enterprise in Vocational Education of responsibility, right and benefit provisions is not clear, nor specific. In practice the lack of maneuverability. These are caused by the enterprises lack the sense of responsibility to participate in school enterprise cooperation.

Currently our country is in the social and economic system during the transition period, many manufacturing enterprises is in transition, structure adjustment and industrial upgrading, relying on advanced technology and improve the quality of staff and workers in the enterprise development business philosophy and intensive development had not been implemented at the operational level. Some enterprises do not recognize the importance of education investment, and they are also the direct beneficiaries of the school enterprise cooperation. In addition, due to the interest allocation mechanism is not perfect, so that enterprises have not been expected to actively participate in school enterprise cooperation in return, which will enable enterprises to participate in the enthusiasm of enterprise cooperation significantly reduced.

\section{Research on the Countermeasures of Promoting the Development of School Enterprise Cooperation}

Establish and Perfect the External Guarantee Mechanism of School Enterprise Cooperation. Under the condition of market economy, the state is based on school enterprise cooperation in personnel training mode of management and constraints, through legal means to, for example, formulate and improve relevant laws and regulations, clearly defined enterprises to participate in school enterprise cooperation in personnel training mode of the rights and obligations. 
The establishment of guide enterprises to participate in the national incentive mechanism of education reform in promoting school enterprise cooperation in personnel training mode should play an important role, through the development of incentive policies and funds as a lever to the establishment of enterprise participation in school enterprise cooperation in investment and subsidy mechanism, to encourage, support and guide the enterprises to participate in the reform of education.

Governments at all levels should take the responsibility to coordinate and promote the cooperation between colleges and enterprises, through the construction of school enterprise cooperation platform, to expand the impact of the school enterprise cooperation model in the whole society. In addition, we should strengthen the supervision and evaluation by way of cooperation platform to further build a service economy and enterprise development of human resources platform.

Strengthening the Connotation Development of School Enterprise Cooperation. In order to adjust and regulate the construction of mechanical specialty, we should carry out the analysis of market demand, adjust the structure of talents training and avoid the disconnection between education and social demand. As for the construction of mechanical specialty, not only to meet the needs of the development of the current manufacturing industry, but also to take into account the long-term development of manufacturing enterprises.

Outstanding Job Skills Training, Innovative Mechanical Professional Course System as School Enterprise Cooperation. An important part of the personnel training mode, mechanical professional curriculum system construction should reflect the mechanical knowledge of the scientific, professional, development, practice and process of, and enterprises will be absorbed into the curriculum development and the construction of to, so as to build a by the open curriculum system in the school and enterprise cooperation construction.

Construction of the school enterprise joint teaching system in order to really play the role of schools and enterprises in the two main bodies in the mechanical personnel training, but also must establish a sound school - enterprise joint teaching system. In this teaching, the emphasis is on the sharing of resources, the complementarity of teaching and the linkage of training. Resource sharing is the sharing of teaching resources, such as the establishment of a high level, to the application of practical teaching oriented teachers.

Teaching of complementarity refers to schools and enterprises should give full play to their respective advantages on the mechanical professional talent training, such as school of intellectual resources and research advantage, advantage of enterprise application ability training and job skills training, talent training showing a complementary state. The linkage of the so-called culture, school and enterprise should training plan, the content and the goal of in-depth and extensive exchanges and make mechanical personnel culture is in line with the school talent training goal, is also in line with the need of enterprise directional positions of the talent, to truly achieve a win-win.

\section{References}

[1] Dong MI, Han Hua, Luo an. Research on the innovation and Entrepreneurship of university students' innovation and Entrepreneurship (J]. Journal of Xiangtan Normal University (SOCIAL SCIENCE EDITION), 2008, 30 (4): 177-178.

[2] Wu Ping, Research on the mode of cooperative education in schools in our country [J]. Management, 2008, 2 (3): 64-67.

[3] Jiang Zhenpeng, Zhang Kai. Exploration and Practice on the reform of talent training mode of work study combination the practice of education and occupation. [J], 2008 (29): 43-44.

[4] Zhang Yan,. Analysis of the talent training mode of enterprise cooperation in Electromechanical Integration Specialty [J].Henan science and technology, 2011 (20): 37

[5] Wang Wang. Research on the power of technological innovation of school enterprise cooperation [D]. Xi'an: Xi'an University of Technology Master's degree thesis, 2007 
[6] Fan Fulan, Zhang Yi, etc. Based on the application effect of micro video teaching resource interactive teaching mode analysis [J]modern educational technology, 2012, (6) PP.24-28.

[7] Paul saettler. The evolution of amerrican educational technology [M]. charlotte; information age publishing, 1990.

[8] Wu Fati. Network curriculum design and development [M]. Beijing: Higher Education Press, 2011. 